\title{
First results of atmospheric electricity measurements by CS110 electric field meter at Paratunka observatory, Kamchatka
}

\author{
Sergey Khomutov ${ }^{1, \star}$, Sergey Smirnov ${ }^{1}$, Stanislav Butin ${ }^{1}$, and Ilkham Babakhanov ${ }^{1}$ \\ ${ }^{1}$ Institute of Cosmophysical Researches and Radio Wave Propagation FEB RAS, \\ Paratunka, Kamchatsky Kray, Russia
}

\begin{abstract}
The results of continuous measurements of AEF potential gradient by CS110 fluxmeter at Paratunka observatory are presented.
\end{abstract}

\section{Introduction}

Atmospheric electric field (AEF) is the object of active scientific investigations. The experimental basis for such investigations is provided by monitoring measurements of AEF at observatories as well as special observations at temporary stations. However, at the present time, there are no standards for such measurements and international or national centers for data collection. Thus, reliability of the obtained results at the observatories is usually ensured by standard procedures of calibration and comparison of devices of different types.

At Paratunka Geophysical Observatory of IKIR FEB RAS, regular observations of AEF have been carried out since 1996 [1]. We use a widely spread sensor "Pole-2" (electric field meter, fluxmeter) to measure the electric field intensity [2]. It ensures reliable and qualitative results that is also due to the self-calibrations and occasional comparisons with other electric field meters, for example, with EF-4 or Gradient-3 [3]. However, this device is out of date instrumentation both structurally (element base and circuit technology) and physically in the result of degradation of the construction mechanical elements. Thereby, IKIR purchased a modern digital electric field meter CS110 (Campbell Scientific, Inc., USA) in November 2015 within the framework of Russian Scientific Foundation Grant. Besides the modernization of instrumentation for AEF monitoring, the task was to compare the results of measurements by electric field meter "Pole-2" with that carried out by the electric field meter CS110 which corresponds to the international standards in the area of AEF observations (for example [4]).

\section{Instrumentation and operation conditions}

The electric field meter CS110 is a device widely spread for AEF investigations, including lightning activity control. Measurements of the vertical gradient of AEF potential $\mathrm{E}_{Z}$ are carried out according to the same methodical principle as in "Pole-2" sensor: electric field modulation by a field mill. However, in comparison to "Pole-2" mill rotating with high speed, CS110 has a modulating mill with reciprocating motion that is provided by a stepper motor. Moreover, the measuring element of

^e-mail: khomutov@ikir.ru 

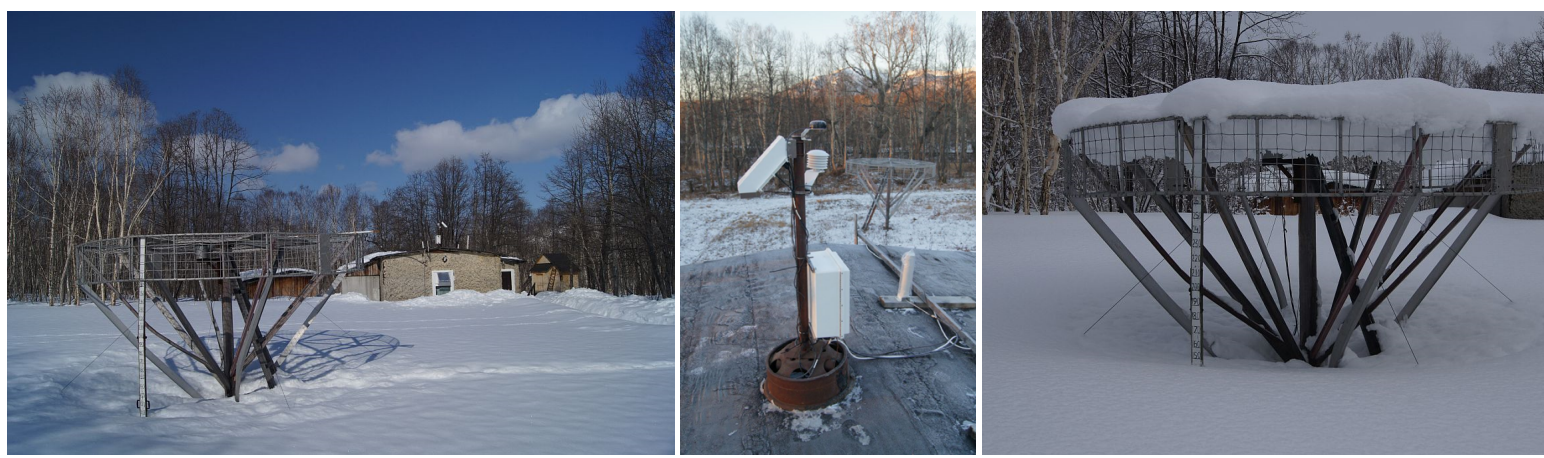

Figure 1. Electric field meters at "Paratunka" observatory. Left panel: pillar with sensor "Pole-2" at its center (in front is a stadia rod to measure the snow depth), the technical hut with the electric field meter CS110 on the roof is in the background. Middle panel: the electric field meter CS110 on a mast on the roof of the technical hut, pillar with "Pole-2" sensor is in the background. Right panel: pillar and sensor "Pole-2" are covered with snow after a cyclone (March 23, 2016).

CS110 sensor is oriented downwards that protects its shutter from precipitation causing problems for "Pole-2" during strong snowfalls. CS110 sensitivity in the range of $\pm 2200 \mathrm{~V} / \mathrm{m}$ is $0.32 \mathrm{~V} / \mathrm{m}$, root mean square value is $0.42 \mathrm{~V} / \mathrm{m}$. There is a capability of automatic switch to an extended range of $\pm 22300 \mathrm{~V} / \mathrm{m}$ (with the loss of sensitivity of about one order). The electric field meter includes a logger CR1000 for control, data collection and exchange with external devices, for example, with a PC. Information transmission to a PC is realized via the WiFi. Inner timer synchronization is provided by PPS-signal of the build-in GPS-receiver. Leakage current, CS110 sensor temperature and humidity are being controlled. Buffer memory and battery supply ensure autonomous measurements within 7 days. Moreover, additional external sensors, for example meteorological ones (temperature, humidity and precipitation) can be connected to the logger.

The electric field meter CS110 (sensor, logger box, GPS-receiver and UPS), GPS antenna and the sensor of the outdoor temperature and humidity were mounted on a special steel pole with solid base on the roof of a technical hut (the area is about $6 \times 6 \mathrm{~m}^{2}$ with bituminous coating, Fig. 1). The sensor, the mast and the box with electronics are grounded. The electric field meter line supply is $220 \mathrm{~V}$. The height of the measuring element of the sensor is $1.2 \mathrm{~m}$ above the roof, the height of the roof above the ground level is $3.7 \mathrm{~m}$. The electric field meter "Pole-2" is installed about $19 \mathrm{~m}$ to the South from CS110 on a frame pier. The shutter height is about $3 \mathrm{~m}$.

The recording laptop with LoggerNet software is placed inside the hut. The measurement frequency is $1 \mathrm{~Hz}$. An output file includes time, potential gradient $\mathrm{E}_{Z}(\mathrm{~V} / \mathrm{m})$, measurement status, leakage current (nA), temperature and humidity inside the sensor $\left({ }^{\circ} \mathrm{C}, \%\right)$, battery voltage of the build-in UPS. A separate file contains the data obtained by 10-minute averaging. Data from the logger buffer memory are recorded into files on schedule (hourly). LoggerNet software displays the results of current measurements in text and graphic forms in on-line mode.

\section{Results}

Regular observations by CS110 began in November 2015, i.e. they covered the winter with snowfalls and low temperatures which cause many problems in AEF measurements. Within the whole period 

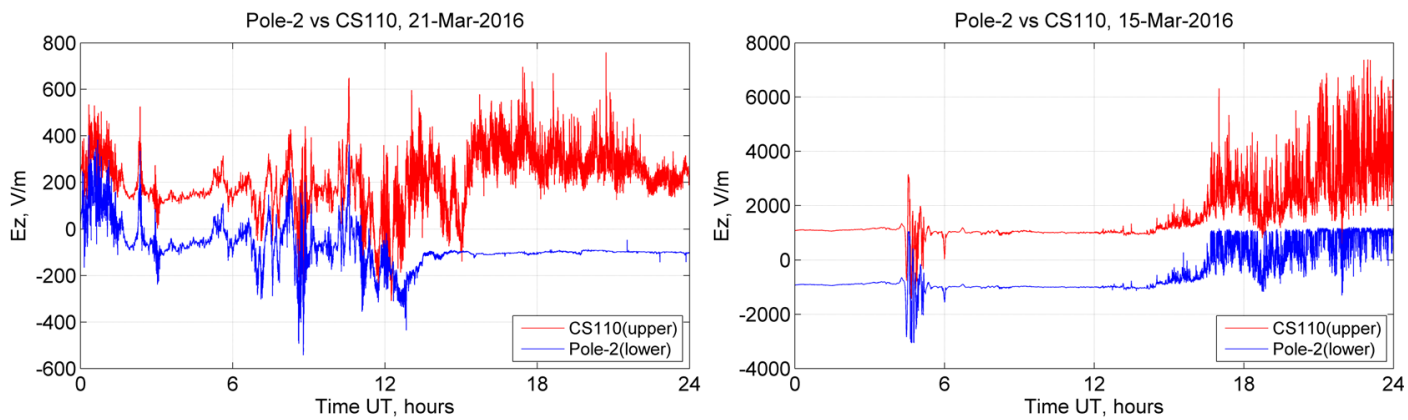

Figure 2. AEF records by electric field meters "Pole-2" and CS110 during extreme weather conditions. Left panel: during a heavy snowfall after 13 UT, "Pole-2" sensor was covered with snow. Right panel: light snow and storm wind after 16 UT cause displacement of "Pole-2" records outside the acceptable limit (CS110 is shifted for better presentation).

under consideration, there were no significant failures in instrumentation operation including the periods of power cutoffs. The initial calibration of the electric field meter CS110 was carried out by the manufacturer and is not required during ordinary operation. However, the results of measurements were not reduced to the ground level by the moment of preparation of the present paper since the corresponding reduction coefficient was not determined due to the snow.

As we noted before, cyclones during cold seasons are accompanied by heavy snowfalls when the snow depth may reach up to 0.5-1.0 m. Fig. 1 (right panel) shows "Pole-2" pier after a cyclone in March 2016. It is clear that the sensor is completely covered with snow. Its readings reduce to the zero. However, CS110 measurements were going on owing to the shutter oriented downwards (Fig. 2, left panel). The second advantage of measurements by CS110 is the extended range of measurements, to $22000 \mathrm{~V} / \mathrm{m}$, in comparison to "Pole-2" capabilities which range is limited to about $\pm 2000 \mathrm{~V} / \mathrm{m}$ (example of a record is in Fig. 2, right panel).

The results of measurements by two electric field meters during fair weather conditions are quite similar. As an example, Fig. 3 shows variations of $E_{Z}$ for one day (February 4, 2016) and one hour (February 9, 2016).

As long as the coefficient of reduction to the ground level for CS110 was not determined, there are regular scale differences in the data which are eliminated from the curve in Fig. 3 by adjustment of the appropriate coefficient. It is clear from Fig. 3 that the results from the both devices are quite similar. For fast variations of $E_{Z}$, the difference variances reach $10-20 \%$ and they are likely to be caused by local AEF dynamics due to the spatial separation of the devices and different time of response on sudden disturbances. Amplitude-phase differences in the records on characteristic times of units-tens of seconds are quite often observed during light wind.

\section{Conclusions}

First regular measurements of potential gradient $\mathrm{E}_{Z}$ were carried out by a new electric field meter (fluxmeter) CS110 at "Paratunka" observatory, IKIR FEB RAS, during quite extreme weather conditions in winter-spring 2016 and without strict metrological basis. Nevertheless, the electric field meter proved to be a reliable and functional device having some advantages in comparison to the standard 

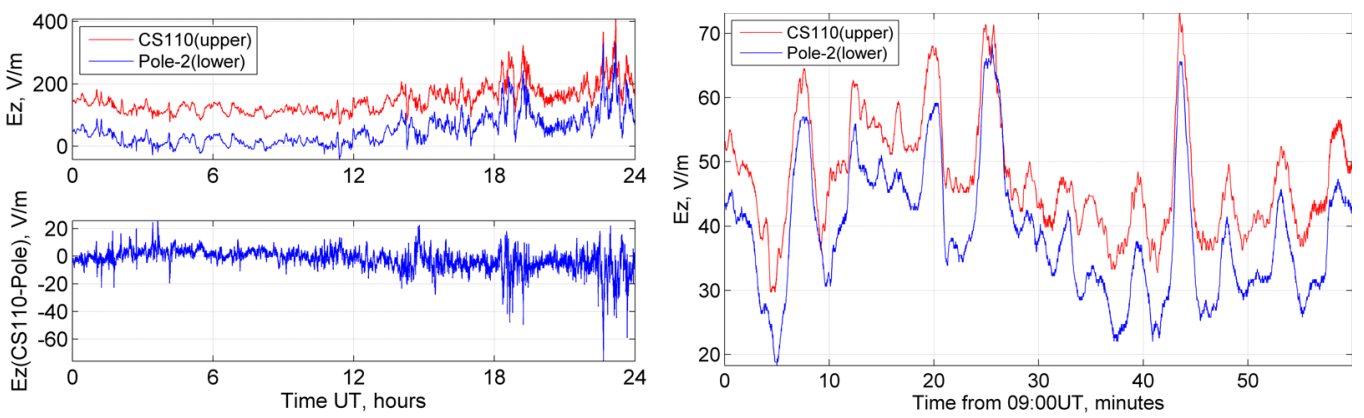

Figure 3. Comparison of variations of $E_{Z}$, obtained by the electric field meters "Pole-2" and CS110 during fair weather conditions. Left panel: daily record on February 4, 2016 (at the top) and their differences (at the bottom). Right panel: hour fragment of the record on February 9, 2016.

field mill "Pole-2" mainly during the observations when weather conditions are far from fair. The results of measurements by CS110 and "Pole-2" show good agreement during normal conditions. The observed differences may be explained by local features of AEF dynamics in the vicinity of the set of spatially separated devices.

In 2016 we plan to calibrate the CS110, taking into account the location, to correlate CS110 and "Pole-2", and to compare it with other electric field meters, with EF-4 for example.

This work was supported by the Russian Science Foundation Grant No. 14-11-00194.

\section{References}

[1] A.V. Buzevich, S.E. Smirnov, 23 General Assembly of the International Union of Geodesy and Geophysics (2003), B81

[2] Datchik napryazhennosti elektricheskogo polya "Pole-2". Tekhnicheskoe opisanie i instruktsiya po ekspluatatsii (A.I. Voeykov GGO, Leningrad, 1991), 35

[3] R.R. Akbashev, P.P. Firstov, S.Yu. Khomutov, V.A. Efimov, Problemy kompleksnogo geofizicheskogo monitoringa Dal'nego Vostoka Rossii (GS RAN, Obninsk, 2015), 197-201 (in Russian)

[4] F.C. Magina et al., XV International Conference on Atmospheric Electricity (Norman, 2014), 111 